\title{
RECENT ADVANCEMENT IN FORENSIC TOXIC DRUG ANALYSIS BY DESORPTION ELECTROSPRAY IONIZATION MASS SPECTROMETRY (DESI-MS)
}

\author{
Ahmed S., Kandiah M.
}

\begin{abstract}
Forensic toxicology is the analysis of biological samples to identify the presence of any harmful substances in the body. The three major sub disciplines in forensic toxicology are; human performance toxicology, post-mortem toxicology and forensic drug analysis. Hence, from the three major sub disciplines in forensic toxicology, forensic drug analysis is of major interest, as it involves in the identification of illicit and counterfeit pharmaceutical drugs in biological matrices. Thus, desorption electrospray ionization mass spectrometry (DESI-MS) is an emerging technique in rapid analysis of biological samples in forensic drug analysis, due to the increase in illicit and counterfeit drug users during the past decade. Although, this technique allows the direct analysis of samples from the surface at ambient pressure, development in the technique has been made to increase the sensitivity and specificity in analysing forensic drugs. Meanwhile, improvements in the extraction procedures prior to DESI-MS analysis, possibilities in analysing the drugs in raw urine sample from its native environment and reduction in the geometrical parameters have been the major developments made in DESI-MS. Also, advancement in DESI-MS enables direct analysis of drug tablets to identify the active pharmaceutical drugs present in the tablet and distinguishes between pharmaceutical drugs and counterfeit or fake drugs. This safety evaluation is important as several counterfeit drugs are prepared with illicit components and sold in the market and used to perform illegal activities. Therefore, the recent advancement in forensic toxic drug analysis by DESI-MS enables the law enforcement to pursue criminal charges against the suspect.
\end{abstract}

\section{Introduction}

Forensic toxicology is the analysis of biological samples to identify the presence of any harmful substances in the body (Peters, 2013). The three major sub disciplines in forensic toxicology are; human performance toxicology, post-mortem toxicology and forensic drug analysis. Human performance toxicology identifies the physical and mental effects of illegal drugs; post-mortem toxicology identifies the cause of death in relation to the harmful substances present in the body and forensic drug analysis monitors the presence of illegal drugs in biological matrices (Llah et al., 2016). Hence, from the three major sub disciplines in forensic toxicology, forensic drug analysis is of major interest, as it involves in the identification of illicit and counterfeit pharmaceutical drugs in biological matrices. Illicit drugs are substances that cause addiction, changes in consciousness and has limited or no use in medical purposes (Ifa et al., 2009). Thus, counterfeit drugs or falsified drugs are contaminated with limited or no active pharmaceutical ingredients (API) causing harmful effects on health. Therefore, by analysing these types of drugs, the law enforcement can pursue criminal charges and the court can determine appropriate sentencing against the suspected individual (Llah et al., 2016). Moreover, illicit drugs can be classified in to different types as shown in table 1, causing behavioural changes in the individual by acting on the central nervous system (CNS) due to prolonged usage of the drug (Jones, 2016). 
Table 1: Summary of the illicit drug types and examples (Jones, 2016).

Classification of Effect on the CNS Examples

illicit drugs

\begin{tabular}{|c|c|c|}
\hline Opiates & $\begin{array}{l}\text { Pain relieving drugs and long term use } \\
\text { of these can cause physical } \\
\text { dependence. }\end{array}$ & $\begin{array}{l}\text { Morphine, heroine, diacetylmorphine } \\
\text { codeine. }\end{array}$ \\
\hline Stimulants & $\begin{array}{l}\text { Increase the activity of the CNS, } \\
\text { causing the individual to be }\end{array}$ & $\begin{array}{l}\text { Amphetamine, methamphetamine, coca } \\
\text { nicotine. }\end{array}$ \\
\hline
\end{tabular}
aggressive.

\begin{tabular}{|c|c|c|}
\hline Hallucinogen & $\begin{array}{l}\text { Causes the individual to imagine or } \\
\text { hear things that do not exist. }\end{array}$ & $\begin{array}{l}\text { Marijuana and Methylenedioxymethamphetamine } \\
\text { (MDMA) }\end{array}$ \\
\hline Depressants & $\begin{array}{l}\text { Decreases the activity of the CNS by } \\
\text { slowing down the normal function of } \\
\text { the brain. }\end{array}$ & Diazepam and Oxazepam \\
\hline
\end{tabular}

Thus, according to the World Drug Report in 2015, the use of illicit drugs has increased globally from 2006 to 2013 as indicated in figure 1 (Unites Nation Office on Drugs and Crime, 2015). The report stated 208 million illicit drug users in 2006 and 246 million users in 2013. Moreover, it has been stated that along with the illicit drug users, there has been an increase in problem drug users. Problem drug users are illicit drug users, suffering from drug use disorder or drug dependence, and 1 out of 10 illicit drug users is a problem drug user. Therefore, this places an additional cost on the treatment of such individuals by the government.

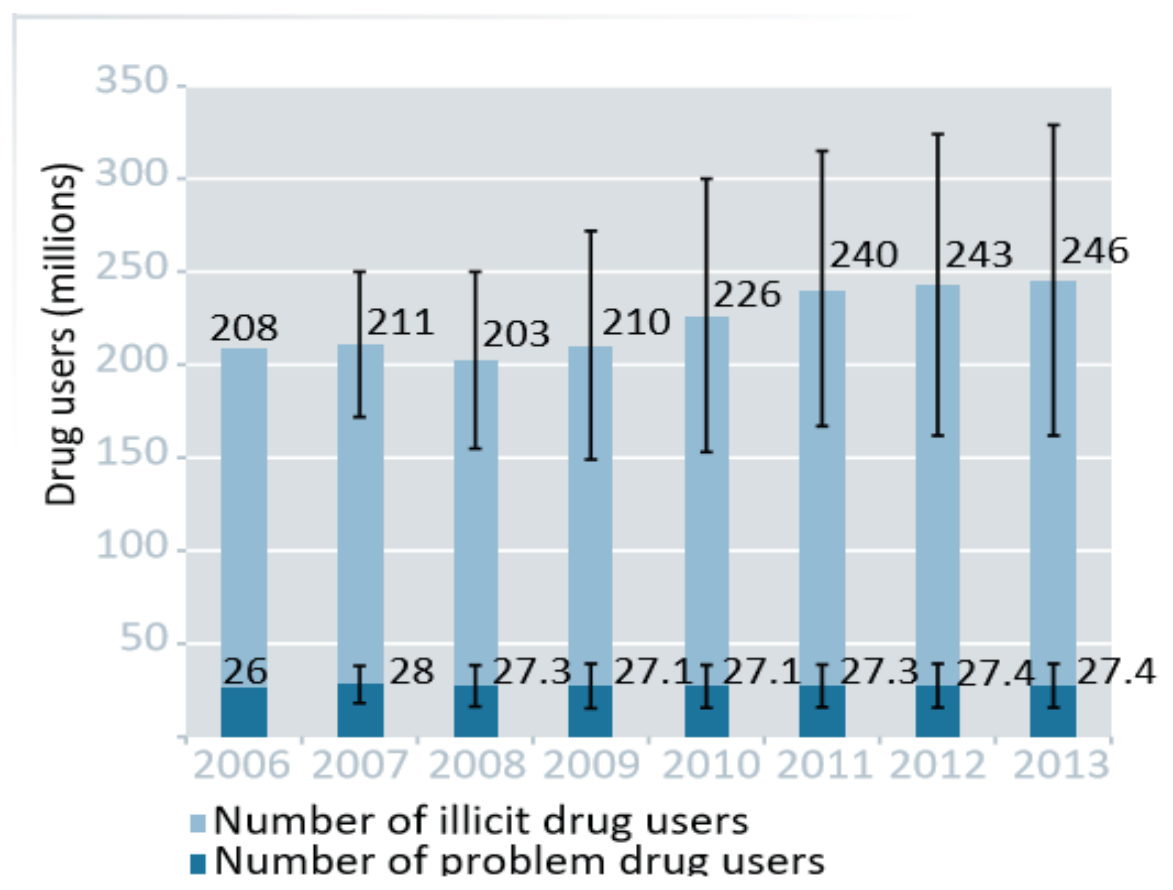

Figure 1: Global trends in the estimated number of illicit and problem drug users, from 2006 - 2013. (Unites Nation Office on Drugs and Crime, 2015). 
Additionally, a report from European Union in 2015 stated a drastic increase in the number of counterfeit drug incidents from 2002 to 2013 (Europol, 2015). It was believed that in 2002 there were about 7553 cases on counterfeit drug usage in United Kingdom (UK) and it increased to 87,000 cases in 2013 as shown in figure 2.

\section{NUMBER OF CASES}

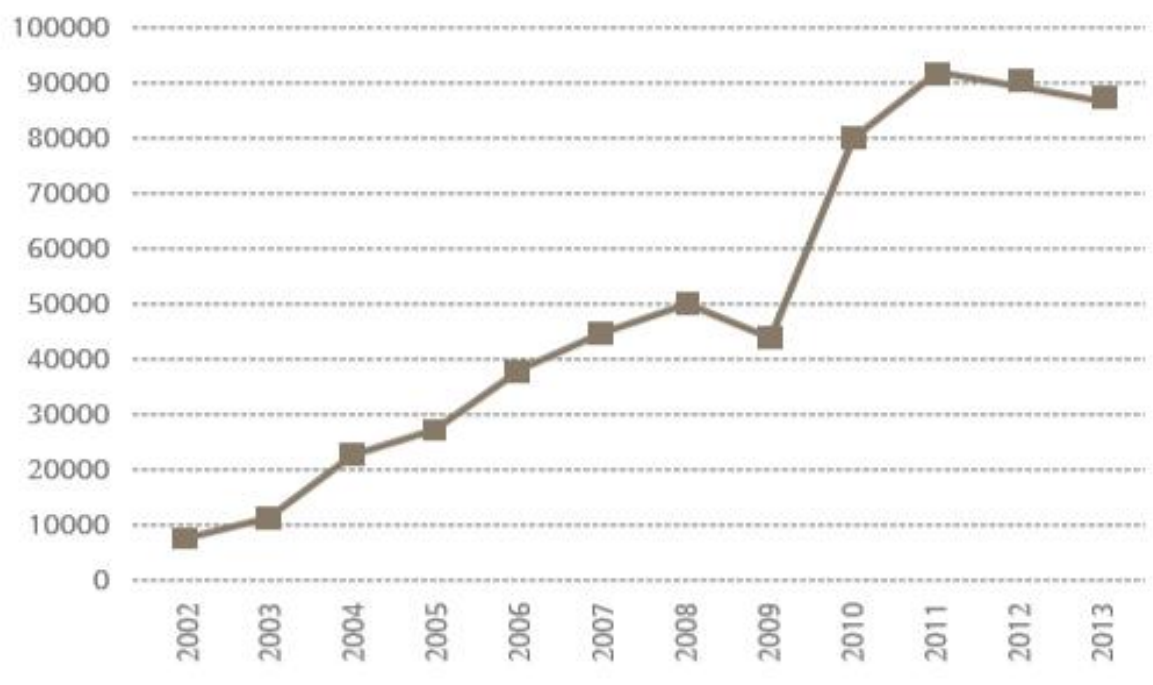

Figure 2: Statistics of the number of counterfeit cases in UK from 2002 to 2013 (Europol, 2015).

Henceforth, prolonged usage of these drugs will cause consequences to the health of the individual, to the society and legal problems of crime scenes and rape cases also arise due to the misuse of the drugs (Lachenmeier and Rehm, 2015). Therefore, rapid testing of the illicit and counterfeit drugs is required for criminal justice. There are two types of test done in forensic drug analysis (Lum and Mushlin, 2004). The screening tests identifies if the suspected drug is present in the sample, by means of a colour change. Therefore, it is less reliable as it does not indicate the quantity of the drug present in the sample. Hence, the confirmatory tests is more reliable as it indicates the quantity of the drug present in the sample, by using analytical technique of liquid chromatography mass spectrometry (LC-MS) and gas chromatography mass spectrometry (GC-MS) (Cooks, 2005). However, these conventional mass spectrometry techniques are time consuming as it requires numerous steps prior to analysis. Therefore, a recently developed analytical technique of ambient ionization mass spectrometry (MS) allows the direct analysis of samples from the surface at ambient pressure providing high sensitivity in forensic drug analysis by overcoming the limitations caused by the conventional mass spectrometry technique (Green et al., 2009). Moreover, there is numerous ambient ionization mass spectrometry techniques developed during the last decade. However, this review will be focused on the advancement in forensic drug analysis by desorption electrospray ionization mass spectrometry (DESI-MS).

\section{Desorption electrospray ionization mass spectrometry (DESI-MS) and its advancement in illicit drug analysis}

DESI-MS was developed by Takáts and co-workers with the help of Professor Graham Cook in 2004 (Takáts et al., 2004). It is the most frequently used ambient mass spectrometry technique in forensic analysis and the process is summarized in figure 3 . Hence, this technique has been used to identify illicit drugs from varieties of surfaces such as paper, plastic, clothes and biological matrices. However, this review will mainly be focused on the analysis of illicit drugs from biological matrices using DESI-MS. 


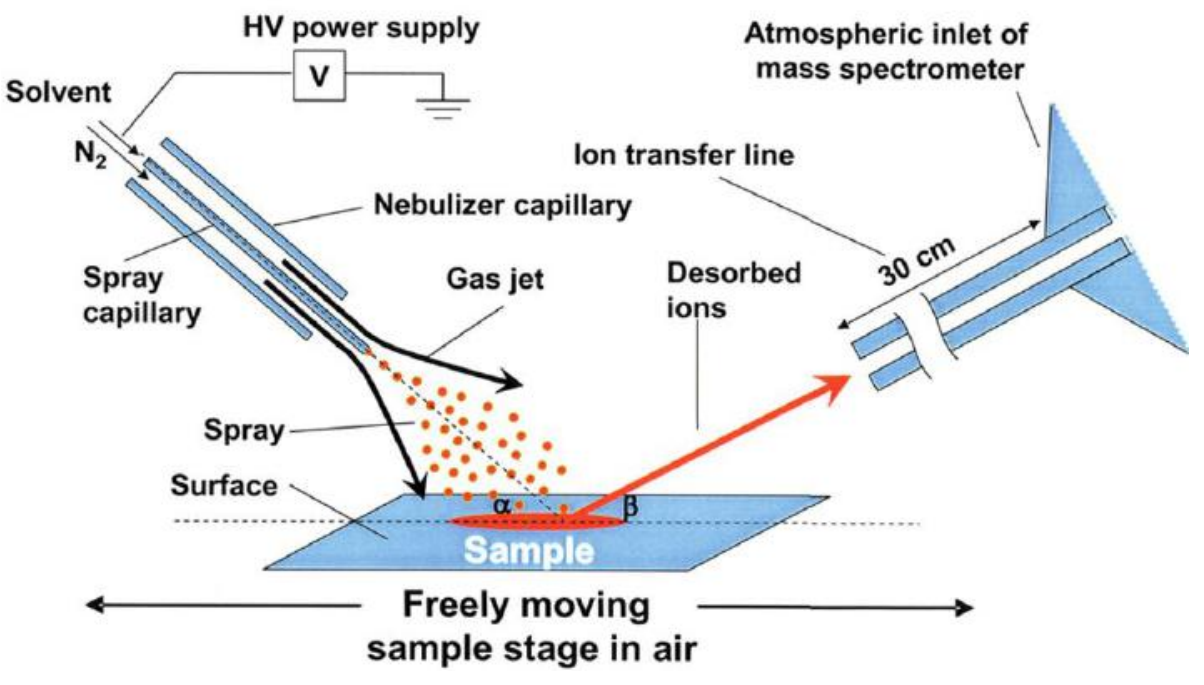

Figure 3: Schematic representation of DESI-MS setup. The DESI-MS process, involves by directing a solvent spray of charged micro-droplet (1:1 methanol : water) from the spray capillary at a specific voltage onto the surface of sample at ambient conditions. These droplets then desorb from the surface (Teflon) and are transported through an atmospheric pressure interface into the mass spectrometry inlet where the solvent is removed under heat and vacuum leaving the ionized form of analyte to be analysed. (Chen and Lin, 2015).

Moreover, in DESI-MS there are specific geometrical parameters $\alpha, \beta, d_{1}$ and $d_{2}$ as shown in figure 4 and table 2 , which has to be taken into consideration, as different analytes require different parameter settings prior to analysis (Takáts et al., 2005).

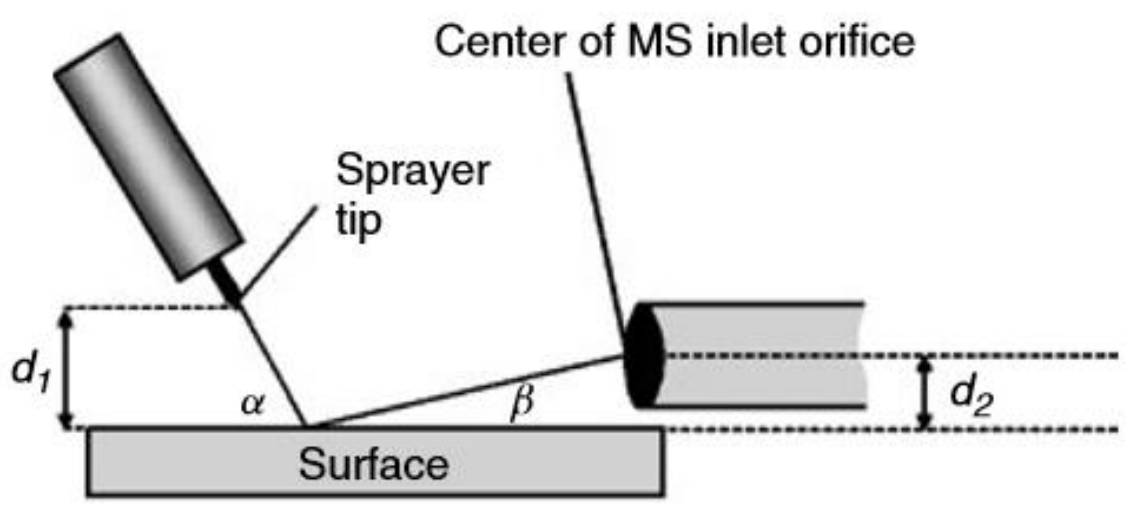

Figure 4: DESI-MS parameters. $\alpha$ : incident angle or solvent spray to surface angle, $\beta$ : ion desorption angle to mass spectrometry inlet $d_{1}$ : solvent sprayer to specimen at surface distance, $d_{2}$ : mass spectrometry inlet to surface distance (Takáts et al., 2005). 
Table 2: Parameters in desorption electrospray ionization mass spectrometry (Takáts et al., 2005).

Parameters Optimum settings for high Optimum settings for low molecular weight molecules (eg: molecular weight molecules (eg: peptides, proteins and drug molecules, explosives, dyes carbohydrates) and lipids)

\begin{tabular}{|c|c|c|}
\hline Electrospray voltage & $1-4 \mathrm{kV}$ & $3-8 \mathrm{kV}$ \\
\hline Electrospray solvent flow rate & $0.1-3 \mathrm{ml} / \mathrm{min}$ & $1.5-5 \mathrm{ml} / \mathrm{min}$ \\
\hline Heated capillary temperature & $200-300{ }^{\circ} \mathrm{C}$ & $200{ }^{\circ} \mathrm{C}$ \\
\hline Nebulizing gas $\left(\mathrm{N}_{2}\right)$ linear velocity & $>350 \mathrm{~m} / \mathrm{sec}$ & - \\
\hline Incident angle $(\alpha)$ & $60-90^{\circ}$ & $20-50^{\circ}$ \\
\hline Ion desorption angle $(\beta)$ & $<10^{\circ}$ & $10-15^{\circ}$ \\
\hline $\begin{array}{l}\text { solvent sprayer to specimen at } \\
\text { surface distance }\left(\mathrm{d}_{1}\right)\end{array}$ & $1-2 \mathrm{~mm}$ & $2-8 \mathrm{~mm}$ \\
\hline $\begin{array}{l}\text { mass spectrometry inlet to surface } \\
\text { distance }\left(\mathrm{d}_{2}\right)\end{array}$ & $1-2 \mathrm{~mm}$ & $5-8 \mathrm{~mm}$ \\
\hline
\end{tabular}

Thus, using DESI-MS, in 2007 Jackson and co-workers performed the first study to identify illicit drugs from a drug mixture as shown in table 3 (Jackson et al., 2007). In this study, 50 nanogram (ng) of drug mixture was dissolved in 1.0 milliliter $(\mathrm{ml})$ of methanol : water $(1: 1)$ and then, 1.0 microliter $(\mu \mathrm{l})$ of the dissolved sample was applied on the Teflon surface and subjected to DESI-MS for analysis. Hence, cocaine, diacetylmorphine and methamphetamine were successfully detected at ng range as shown in table 3 and figure 5 .

Table 3: Summary of drugs analysed using DESI-MS (Jackson et al., 2007).

\begin{tabular}{l|l|l|l} 
Drug & Molecular weight & $\begin{array}{l}\text { Amount analyzed } \\
\text { using DESI }(\mathrm{ng} / \mathrm{mL})\end{array}$ & $\begin{array}{l}\text { Limit of detection } \\
(\mathrm{ng} / \mathrm{mL})\end{array}$ \\
\hline Cocaine & 303 & 50 & 10.8 \\
\hline Diacetylmorphine & 369 & 50 & 10.8 \\
\hline Methamphetamine & 150 & 50 & 10.8
\end{tabular}

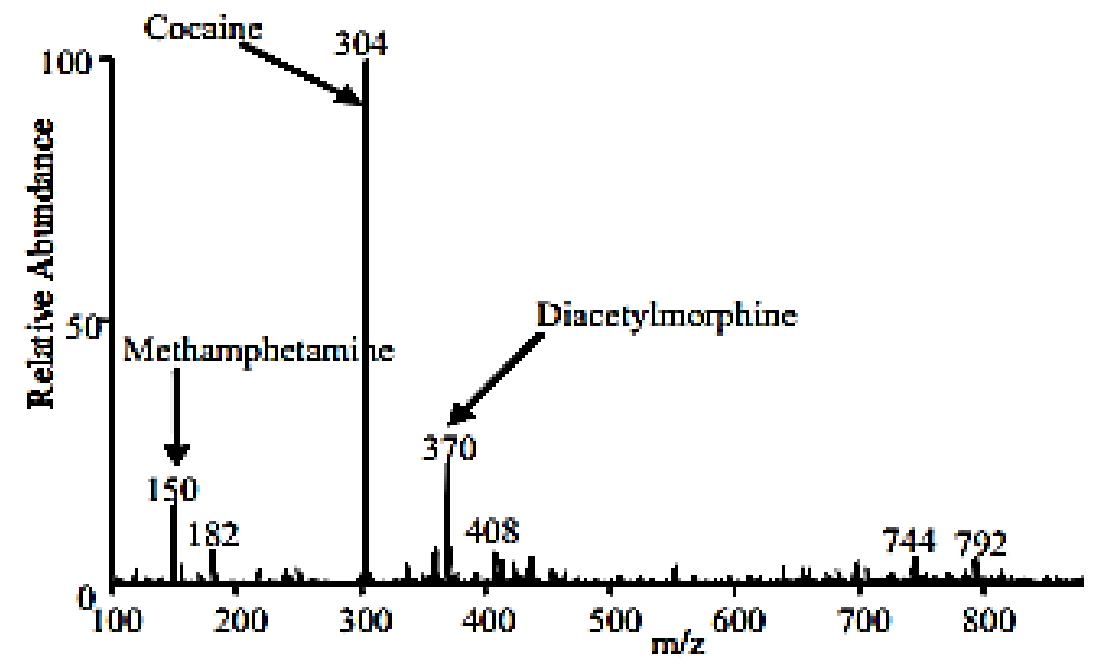

Figure 5: DESI-MS mass spectra obtained for the three different illicit drugs analysed. The solvent spray used was methanol : water (1:1) (Jackson et al., 2007). 
Afterwards, in the same year another study was conducted by Kauppila and co-workers to identify the presence of illicit drugs in patient urine samples (Kauppila et al., 2007). In this study urine sample was extracted by liquid-liquid extraction (LLE) and $1.0 \mathrm{ml}$ of extracted sample was dissolved in $1 \mathrm{ml}$ of methanol : water (1:1). Then, $1.0 \mu \mathrm{l}$ of the dissolved sample was applied on the Teflon surface, allowed to dry and subjected to DESIMS for analysis. Hence, the outcome of this study indicated a group of illicit drugs determined at ng level as shown in table 4

Table 4: Summary of drugs identified in patient urine samples using DESI-MS (Kauppila et al., 2007).

\begin{tabular}{|c|c|c|c|c|}
\hline Drug & $\begin{array}{l}\text { Molecular } \\
\text { weight }\end{array}$ & $\begin{array}{l}\text { Limit of detection } \\
(\mathrm{ng})\end{array}$ & Solvent spray & Sample \\
\hline Temazepam & 300 & 10.4 & $\begin{array}{l}\text { Water: formic acid } \\
(100: 0.1 \%)\end{array}$ & 1 \\
\hline Oxazepam & 286 & 17.8 & & \\
\hline Desmethyldiazepam & 270 & 0.68 & & \\
\hline Codeine & 299 & 1.9 & $\begin{array}{l}\text { Water: acetonitrile (10: } \\
90 \%)\end{array}$ & 2 \\
\hline Morphine & 285 & 2.4 & & \\
\hline Amphetamine & 135 & 2.2 & $\begin{array}{l}\text { Water: acetonitrile (10: } \\
90 \%)\end{array}$ & 3 \\
\hline
\end{tabular}

Typically, DESI-MS is used to analyse solid samples, and to analyse liquid samples such as urine and blood; the sample has to be dried prior to analysis as discussed earlier. The dried sample by DESI-MS results in incomplete analysis of analytes from its native environment, due to the consumption of analytes on the surface (Zheng and Chen, 2016). Additionally, the high velocity of nitrogen gas projected by DESI-MS can result in splashing of the liquid sample on the surface. Therefore, due to these limitations, in 2009 Miao and Chen improved the DESI-MS developed by Takáts and co-workers in 2004, to directly analyze liquid samples such as urine and blood by a technique known as liquid DESI-MS (Miao and Chen, 2009). In this technique as shown in figure 6, liquid DESI-MS allows direct analysis of liquid sample from its native environment, allowing a continuous flow of sample to the Teflon surface through a fused silica capillary, overcoming the limitations caused by the traditional DESI-MS. 


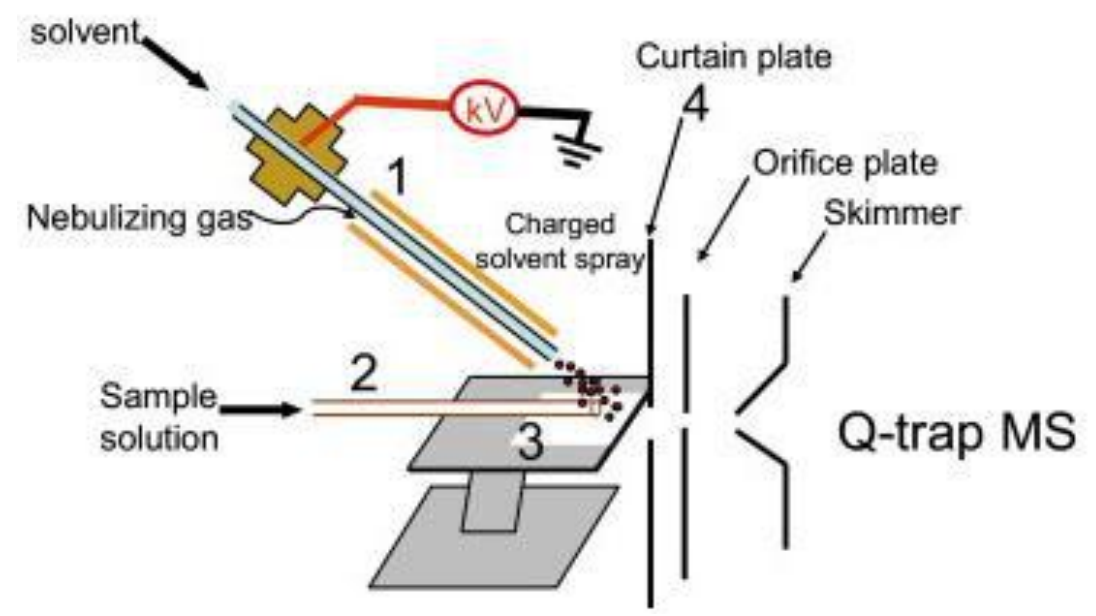

Figure 6: Schematic representation of liquid DESI-MS setup. (1) The solvent spray source (2) Fused silica capillary (3) Teflon surface to desorb and analytes into the mass spectrometry inlet (4) The analytes are analysed by Quadrapole- trap mass spectrometry (Miao and Chen, 2009).

Hence, to confirm the study, the technique was used to analyse raw urine sample spiked with illicit drug methamphetamine. Hence, a mass spectrum of methamphetamine analyte at mass to charge ratio (m/z) 150 was detected as shown in figure 7.

\section{a)}

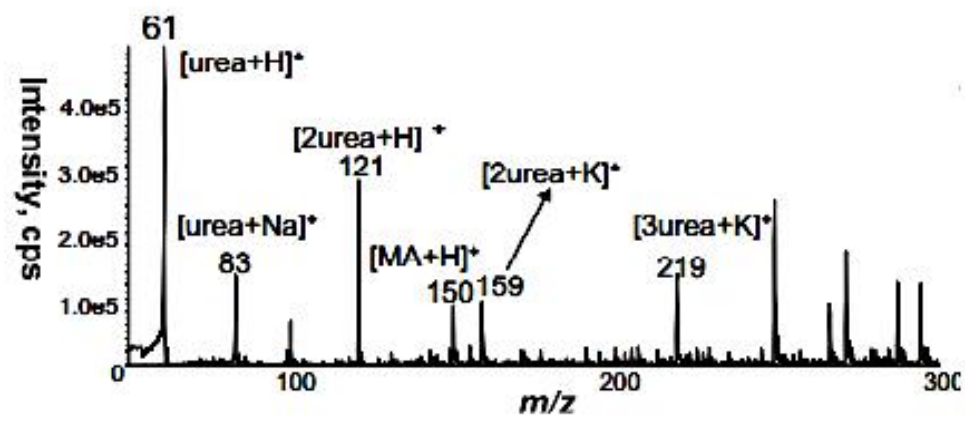

Figure 7: a) liquid DESI-MS mass spectra of methamphetamine $(1 \mu \mathrm{g} / \mathrm{mL})$ in raw urine sample and DESI solvent spray was methanol : acetic acid (1:0.03 by volume). The formation of fragment ions along with the analyte ion at $\mathrm{m} / \mathrm{z}$ ratio 150 , confirms the presence of methamphetamine (Miao and Chen, 2009).

Additionally, the liquid-liquid extraction used in traditional DESI-MS prior to analysis is relatively time consuming as it requires the separation of organic layer with the sample from the aqueous layer (Laskin and Lanekoff, 2016). Moreover, large amount of solvent and sample is required for extraction. This can be a major drawback, as samples obtained in forensic cases are of limited quantity. Therefore, considering the above stated drawbacks of liquid-liquid extraction procedure, DESI-MS was improved with an extraction procedure known as solid phase microextraction (SPME). SPME consists of a polymer fibre coated material, with extracting components involved in extracting analytes from different media (Mirabelli, Wolf and Zenobi, 2016). Importantly, SPME has several advantages when compared with the traditional extraction procedure of liquidliquid extraction. It is easy to automate and allows the usage of solid, liquid and gaseous samples. Also, it can be used as a portable device due to its small size which makes the extraction procedure more convenient in forensic 
drug analysis (Yazdi and Amri, 2010). Furthermore, the analytes are separated by desorption and not by separation proving to be less time consuming in providing rapid result in forensic drug analysis. Hence, in 2010 the SPME DESI-MS was used to analyse opiates (illicit drugs) from raw urine sample (Kennedy et al, 2010). In this study $500.0 \mathrm{ng}$ of respective drug was dissolved in $1.0 \mathrm{ml}$ of raw urine sample and to this prepared sample, the SPME fibre coated with $\mathrm{C}_{18}$ silica was dipped for a short period of time as shown in figure 8 . During this time the analytes in the urine adsorbs on to the fibre surface, setting up equilibrium between the analytes and the coating on fibre material. Afterwards, the SPME fibre with the analyte was subjected to DESI-MS as shown in figure 9 for analysis. The results of the study are indicated in table 5 with the respective lower limit of quantification of each drug.

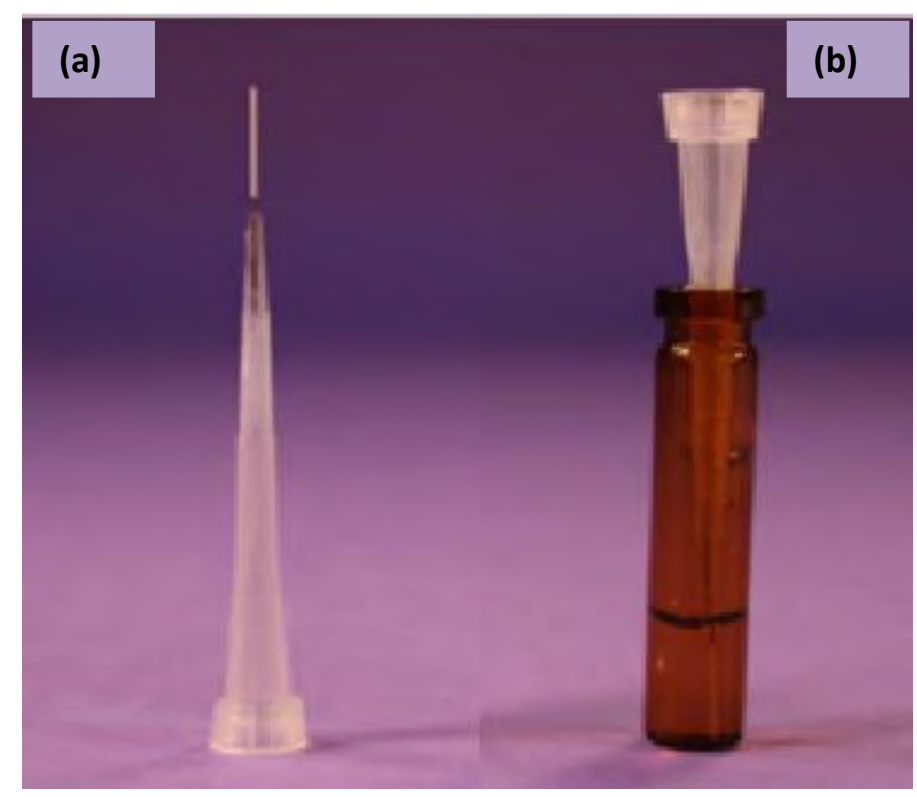

Figure 8: The SPMEfibre used in the analysis of opiates in raw urine sample. (a) The overview of SPME fibre (b) SPME fibre dipped in the respective sample solution set up equilibrium between the analytes and fibre coating (Kennedy et al., 2010).

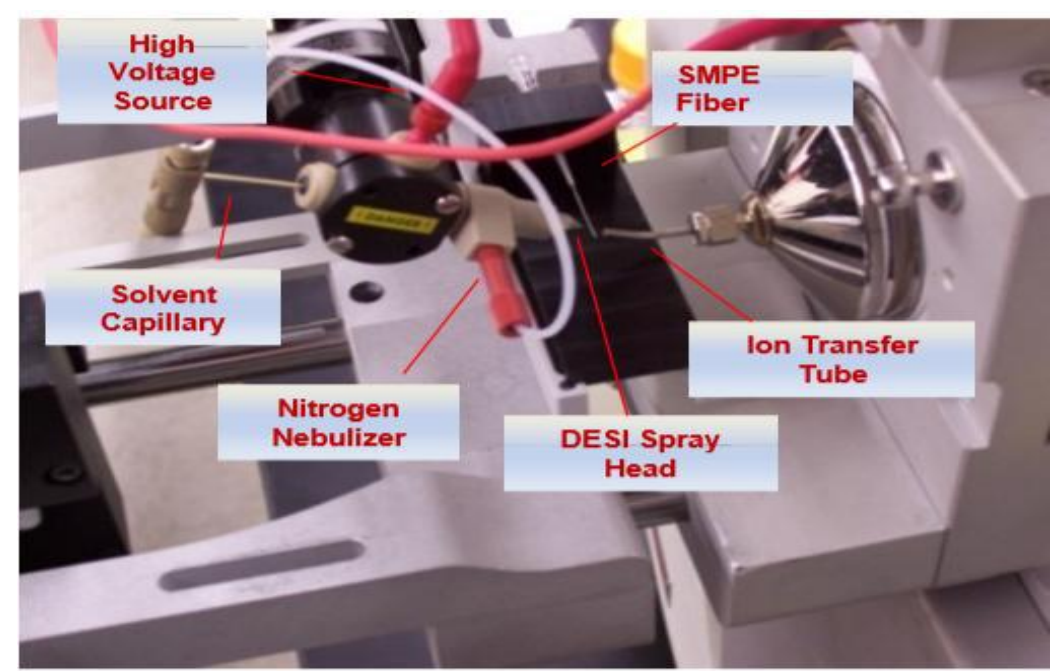

Figure 9: SPME DESI-MS setup for the analysis of opiates in raw urine sample (Kennedy et al., 2010). 
Table 5: Summary of the illicit drugs (opiates) analysed by SPME DESI-MS. The solvent spray used was 1:1 methanol : water (Kennedy et al., 2010).

\begin{tabular}{lll} 
Drug & $\begin{array}{l}\text { Amount analyzed using SPME } \\
\text { DESI-MS }(\mathrm{ng} / \mathrm{mL})\end{array}$ & $\begin{array}{l}\text { Lower limit of quantification } \\
(\mathrm{LLOQ}) /(\mathrm{ng} / \mathrm{mL}\end{array}$ \\
\hline Morphine & 500 & 36.1 \\
\hline Hydrocodone & 500 & 2.83 \\
\hline Oxymorphone & 500 & 46.8 \\
\hline Oxycodone & 500 & 42.8 \\
\hline Methadone & 500 & 2.77 \\
\hline 2-Ethylidene-1,5-Dimethyl-3,3- & 500 & 0.26
\end{tabular}

Diphenylpyrrolidine (EDDP)

However, SPME fibres can be relatively costly and the extracting material coated on the fibre surface has the chance of wearing off (Rutkowska et al., 2014). Therefore, in 2011 another extraction technique known as single droplet microextraction (SDME) was coupled with DESI-MS for the analysis of an illicit drug methamphetamine in raw urine sample (Sun et al., 2011). This study was performed to obtain a single droplet of the analyte from the sample by three steps. Initially, as shown in figure 10 (a), $50.0 \mu$ l of hexamine was added to the sample tube with methamphetamine, from the syringe and was stirred using the magnetic stirrer for 15 minutes at 11,000 rates per minute (rpm). Secondly, $4.0 \mu \mathrm{l}$ of 5\% acetic acid was added to the organic hexane layer and stirred for another 40 minutes at $11,000 \mathrm{rpm}$ to obtain a single droplet of methamphetamine drug. Finally, the extracted single droplet of methamphetamine was withdrawn back into the syringe and coupled with DESI-MS for the analysis of the drug a shown in figure 10 (b).
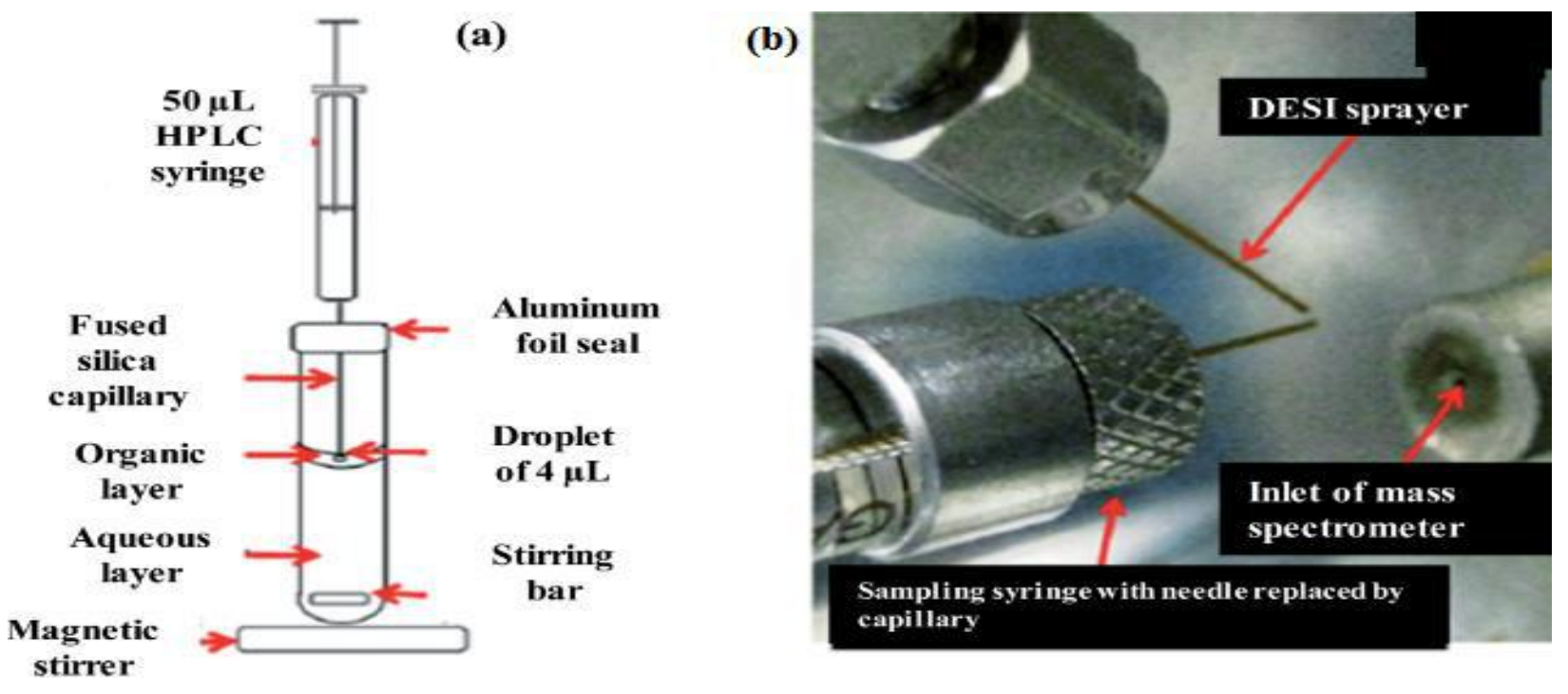

Figure 10: a) Three-phase SDME setup for methamphetamine analysis b) image showing the direct desorption and ionization of the single droplet methamphetamine by DESI-MS (Sun et al., 2011).

And, the results obtained from this study was compared with the liquid DESI-MS of methamphetamine and as shown in table 6, SDME DESI-MS had a lower detection limit of methamphetamine in comparison to liquid DESI-MS. Therefore, the study reveals that SDME DESI-MS is more sensitive in the detection of methamphetamine when compared to liquid DESI-MS.

Table 6: comparison of liquid DESI-MS and SDME DESI-MS to detect methamphetamine in raw urine sample 


$\begin{array}{llll}\text { Molecular } & \text { Technique } & \text { LOD/ } & \text { LOQ } \\ \text { weight } & \text { used } & (\mathrm{ng} / \mathrm{ml}) & (\mathrm{ng} / \mathrm{ml})\end{array}$

\begin{tabular}{lllll}
\hline Methamphetamine & 150 & $\begin{array}{l}\text { Liquid } \\
\text { MS }\end{array}$ & DESI- $200 \quad-$
\end{tabular}

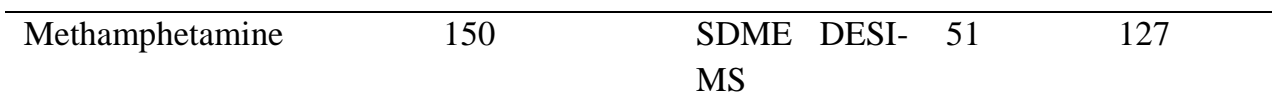

Interestingly, SDME DESI-MS technique had two improvements when compared to the earlier discussed DESI techniques (Sun et al., 2011). Firstly, as seen in figure 10 (b) there was no platform used and secondly the metallic surface of syringe with the micro droplet was replaced by a fused silica capillary avoiding it acting as a platform which might cause partial neutralization of analytes, leading to weak mass spectrometry signals.

However, the SDME procedure is relatively time consuming as it takes one hour for the extraction to complete and the technique can sometimes be less precise in obtaining the droplet of analyte due to prolonged agitation of sample (Rutkowska et al., 2014). Therefore, another extraction method known as thin liquid membrane extraction (TLME) was coupled with DESI-MS in 2013 to analyse illicit drugs of depressants and opiates from urine, blood and saliva (Rosting et al., 2013). In this technique the analysis of each sample was performed within 15 minutes. Firstly, as seen in figure 11, $1.5 \mu \mathrm{l}$ of organic solvent of hexadcane was deposited on a porous Teflon membrane forming a liquid and to the thin liquid layer, sample was added for extraction. Afterwards, the lid was placed and vortexed for 10 minutes to allow extraction and the extracted sample on the thin layer membrane was subjected to DESI-MS for analysis. Interestingly, this technique had a similar principle as the liquid DESI-MS introduced by Miao and Chen. However, the major difference is the analysis being performed on an organic layer rather than a liquid phase.
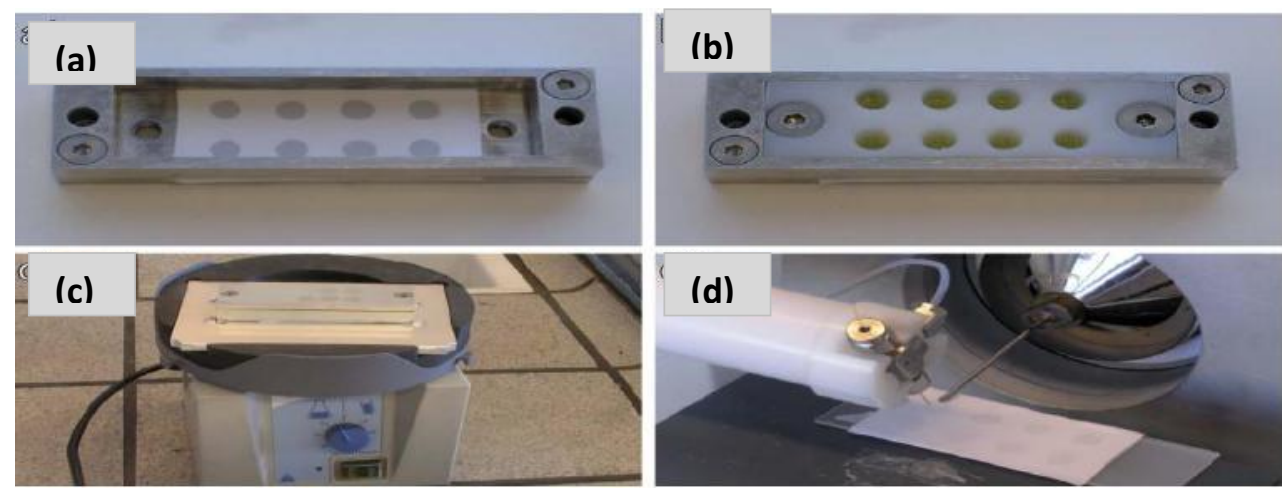

Figure 11: Steps involved in TLME-DESI (a) deposition of hexadecane on a porous Teflon membrane forming a liquid $b$ ) addition of sample to the layer c) the lid was placed and vortexed for 10 minutes to allow extraction d) DESI-MS analysis (Rosting et al., 2013).

Thus, according to table 7, the respective drugs were analysed from saliva, urine and blood samples. 
Table 7: Summary of the non-polar drugs analyzed in three biological fluids using TLME-DESI (Rosting et al., 2013).

\begin{tabular}{lllll} 
Sample type & Drug & Molecular weight & $\begin{array}{l}\text { Physiological } \\
\text { concentration }(\mathrm{ng} / \mathrm{ml})\end{array}$ & $\begin{array}{l}\text { Limit } \\
\text { detection(LOD) } \\
(\mathrm{ng} / \mathrm{ml})\end{array}$ \\
\hline Urine & & & 25 & 17 \\
& Amphytiphyline & 278 & 25 & 17 \\
& Notriptyline & 264 & 25 & 17 \\
& Pethidine & 248 & & 4 \\
\hline Saliva & Methadone & & 25 & - \\
& Amphytiphyline & 278 & 25 & - \\
& Notriptyline & 264 & 25 & - \\
\hline Blood & Pethidine & 248 & 100 & -
\end{tabular}

Although, TLME DESI-MS technique was successful in analysing various biological matrices (blood, urine and saliva), it is only applicable in the determination of non-polar drugs. Therefore, improvements need to be done on the technique for it to analyse polar drugs.

\section{Desorption electrospray ionization mass spectrometry (DESI-MS) and its advancement in counterfeit drug analysis}

Direct analysis of drug tablets involves in the identification of APIs present in the tablet and distinguishes between active pharmaceutical drugs and counterfeit drugs (Xie et al., 2015). This is important as several counterfeit drugs are prepared with illicit components and sold in the market and used to perform illegal activities. Therefore, in forensic drug analysis the analysis of counterfeit drugs are of great concern as mentioned prior for criminal justice and to trace the possible source of the counterfeit (Fernandez et al., 2006). Hence, using DESI-MS developed by Takáts and co-workers in 2004 can be used to analyse counterfeit drugs. And, using this technique aspirin tablet was analysed directly to identify the APIs in the tablet and as indicated in figure 12, aspirin tablet was identified at an abundance of 90 with a mass to charge ration of 179 (Green et al., 2009).

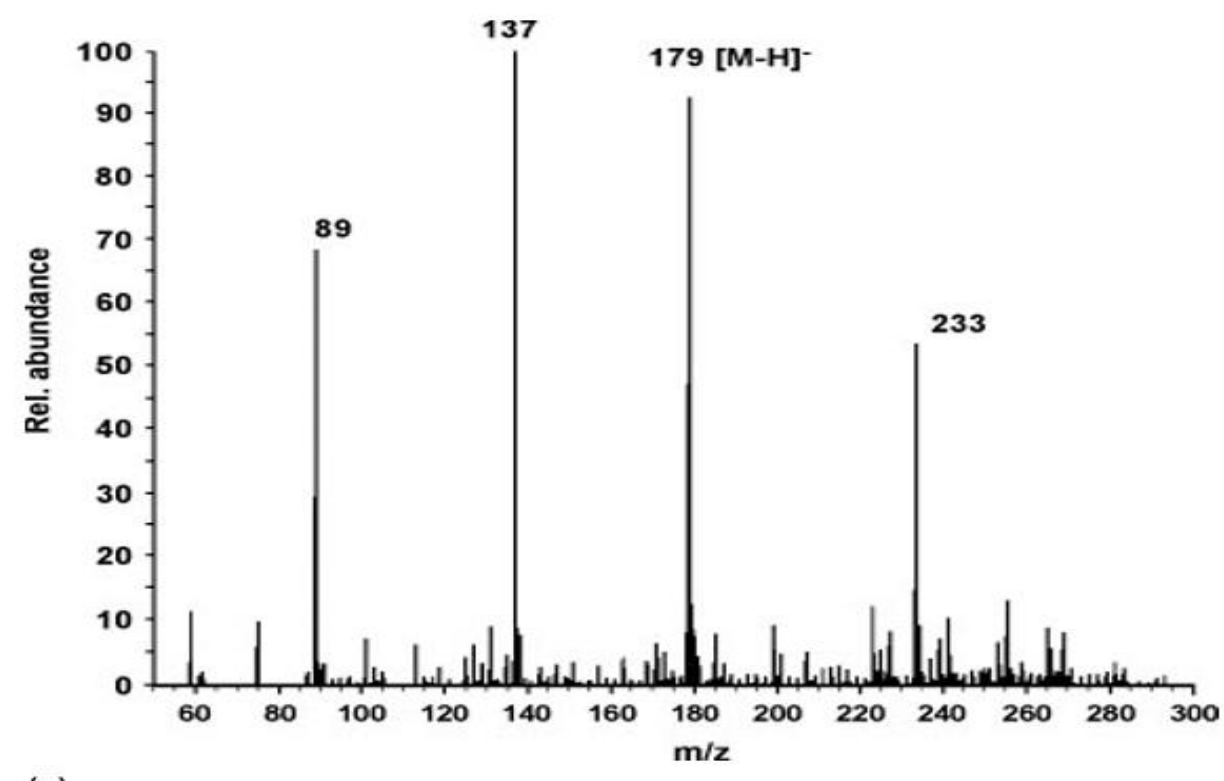

Figure 12: Direct analysis of aspirin tablet using DESI-MS (Green et al., 2009). 
However, the geometrical parameters in DESI-MS as mentioned in figure 4, are of great concern, as slight changes within the parameters will result in weak mass spectrometry signal if the analyte fails to desorb from the surface to the mass spectrometry inlet (Morelato et al., 2013). Therefore, in 2010 Roach and co-workers developed the DESI-MS and named it as nano-spray DESI-MS (Roach et al., 2010). Nano-spray DESI-MS uses a self-aspirating nanospray to ionize the analyte and transport the analyte to the mass spectrometry inlet as shown in figure 13 (Roach et al., 2010). This technique thereby reduces the geometrical parameters of ion desorption angle to mass spectrometry inlet $(\beta)$ and mass spectrometry inlet to surface distance $\left(\mathrm{d}_{1}\right)$, required by the traditional DESI-MS (Green et al., 2009). As a result, the number of analyte reaching the mass spectrometry inlet becomes precise resulting in sensitive detection of analytes.

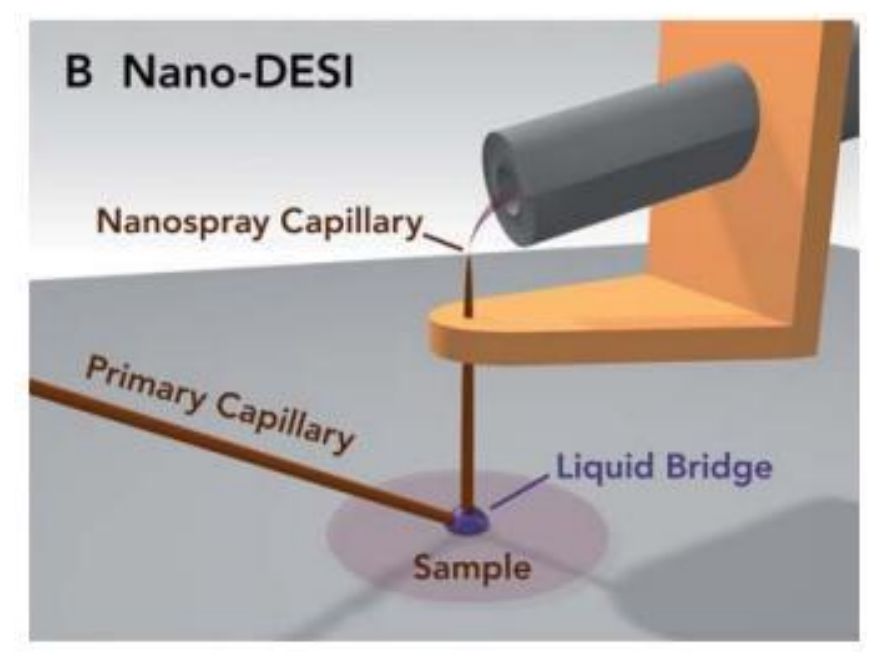

Figure 13: Nano-DESI setup. A liquid bridge formed between the primary capillary and nano-spray capillary. The analyte containing solvent is ionized and removed by self-aspiration nanospray into the mass spectrometry inlet (Roach et al., 2010).

Therefore, in 2016 Palcios and Lanekoff applied the technique to detect the biologically active pharmaceutical ingredients in different tablets as shown in table 8 (Palcios and Lanekoff, 2016). The surface of the tablet was cut using a blade and directly exposed to nano DESI-MS for analysis. Hence, it was concluded that this technique successfully analysed the active pharmaceutical ingredients of the tablets, indicating that nano DESIMS is a powerful and useful technique in forensic drug analysis of counterfeits.

Table 8: Summary of the APIs analyzed, molecular weight and detected $\mathrm{m} / \mathrm{z}$ ions from the surveyed tablets (Palcios and Lanekoff, 2016).

\begin{tabular}{ll} 
Active pharmaceutical ingredient (API) & Detected peaks $(\mathrm{m} / \mathrm{z})$ \\
\hline Ibuprofen $\left(\mathrm{C}_{13} \mathrm{H}_{18} \mathrm{O}_{2}\right)$ & 119 \\
MW= $206.3 \mathrm{~g} / \mathrm{mol}$ & 161 \\
& $207[\mathrm{M}+\mathrm{H}]^{+}$ \\
\hline Paracetamol $\left(\mathrm{C}_{8} \mathrm{H}_{9} \mathrm{NO}_{2}\right)$ & 110 \\
$\mathrm{MW}=151.2 \mathrm{~g} / \mathrm{mol}$ & $152[\mathrm{M}+\mathrm{H}]^{+}$ \\
& $174[\mathrm{M}+\mathrm{Na}]^{+}$ \\
\hline Sildenafil $\left(\mathrm{C}_{22} \mathrm{H}_{30} \mathrm{~N}_{6} \mathrm{O}_{4} \mathrm{~S}\right)$ & $475[\mathrm{M}+\mathrm{H}]^{+}$ \\
MW= 474.6 g/mol & $497[\mathrm{M}+\mathrm{Na}]^{+}$ \\
& $513[\mathrm{M}+\mathrm{K}]^{+}$ \\
& $949[2 \mathrm{M}+\mathrm{H}]^{+}$ \\
& $971[2 \mathrm{M}+\mathrm{Na}]^{+}$ \\
\hline Tadalafil $\left(\mathrm{C}_{22} \mathrm{H}_{19} \mathrm{~N}_{3} \mathrm{O}_{4}\right)$ & 268 \\
MW= 389.4 g/mol & $412[\mathrm{M}+\mathrm{Na}]^{+}$
\end{tabular}




\section{Summary}

DESI-MS is one of the rapidly developing ambient ionization MS techniques due to its speed of analysis and minimum sample preparation. It is a well-used technique in forensic drug analysis of illicit drugs and counterfeit drugs. Hence, this review has mainly highlighted on the advancement in forensic drug analysis by DESI-MS.

In the application of DESI-MS in forensic drug analysis of illicit drugs, several improvements have been made in the technique. Firstly, the built up of an instrumental setup of liquid DESI-MS to analyse illicit drugs directly from urine sample have been achieved without the need of sample being dried in traditional DESI-MS which might be time consuming. Secondly, the liquid-liquid extraction procedure in traditional DESI-MS was improved to obtain results with minimum wastage of sample and cost, by coupling the solid phase micro extraction procedure with DESI-MS. Afterwards, another extraction procedure of single droplet micro extraction was coupled with DESI-MS to improve the sensitivity of the technique. Henceforth, SDME DESIMS technique proved to be more sensitive in analysing the illicit drug methamphetamine in comparison to liquid DESI-MS. Finally, another less time consuming extraction technique known as thin liquid membrane extraction was coupled with DESI-MS to analyse illicit drugs in different biological matrices. Importantly, compared with the other stated DESI-MS techniques which only analysed urine sample, this technique was successful in analysing drug in other biological matrices of blood and saliva.

Furthermore, in the application of DESI-MS in forensic drug analysis of counterfeit drugs, only one improvement was achieved. The development of nano-DESI-MS was developed to overcome the difficulties obtained in adjusting the geometrical parameters in traditional DESI-MS. Henceforth; this technique was successful in analysing several APIs in several types of drugs regularly sold in the market. Therefore, in summary there have been numerous developments of DESI-MS in forensic drug analysis

\section{Future scope}

Although, successful advancement of DESI-MS has been achieved in forensic drug analysis, it requires additional studies to identify the actual sensitivity of the techniques to different types of drugs, as each drug behaves differently to each developed technique. Therefore, in future, extensive research needs to be performed to identify the sensitivity and specificity of each discussed DESI-MS technique in this review on all the type of illicit drugs and counterfeit drugs. Henceforth, the TLME DESI-MS was successful in analysing non-polar drugs and developments need to be done on the technique to analyse polar drugs. Importantly, the developed techniques were mainly subjected to analyse drugs in urine sample and additional studies need to be conducted on other biological matrices such as blood and saliva. Finally, the studies stated in this review are performed on homogenous or relatively clean samples and in forensic drug analysis the samples obtained are relatively unclean. Therefore, the discussed techniques in this review needs to be performed on realistic forensic cases, before they are routinely used by forensic laboratories.

\section{References}

Chen, C.C. \& Lin, P.C. (2015) Monitoring of chemical transformations by mass spectrometry, Analytical Methods, 7 (1), 6947-6959.

Cooks, G. (2005) Desorption electrospray ionization of explosives on surfaces: sensitivity and selectivity enhancement by reactive desorption electrospray ionization, Analytical Chemistry, 77(2), 6755-6764.

Europol (2015) Situation Report on Counterfeiting in the European Union, at stasu.mx.tl/2015-situation-reporton-counterfeiting-in-the-european-union.pdf, visited 20 October 2016.

Fernandez, F.M., Cody, R.B., Green, M.D., Hampton, C.Y., McGready, R., Sengaloundeth, S., White, N.J. \& Newton, P.N. (2006) Characterization of solid counterfeit drug samples by desorption electrospray ionization and direct analysis-in-real-time coupled to time-of-flight mass spectrometry, ChemMedChem, 1 (1), 702-705.

Green, F.M., Salter, T.L., Stokes, P., Gilmore, I.S. \&O'Connor, G. (2009) Ambient mass spectrometry: advances and applications in forensics, Surface Interface Analysts, 42 (3), 347-357. 
Ifa. D.R., Jackson, A.U., Paglia, G. \& Cooks, R.G. (2009) Forensic application of ambient ionization mass spectrometry, Analytical and Bio analytical Chemistry, 392, 1995-2008.

Jackson, A.U., Talaty, R.G,. Cooks,G.J. \& Berkel, V. (2007) Salt tolerance of desorption electrospray ionization (DESI), Journal of American Society and Mass Spectrometry, 18 (4), 2218-2224.

Jones, J.T. (2016) Advances in drug testing for substance abuse alternative programs, Journal of Nursing Regulation, 6 (1), 60-65.

Kauppila, T.J., Talaty, N., Kuuranne, T., Kotiaho, T., Kostiainen, R. \& Cooks, R.G. (2007) Rapid analysis of metabolites and drugs of abuse from urine samples by desorption electrospray ionization-mass spectrometry, The Analyst, 132 (5), 868-875

Kennedy, J.H., Aurand, C., Shirey, R., Laughlin, B.C. \& Wiseman, J.M. (2010) Coupling desorption electrospray ionization with solid-phase microextraction for screening and quantitative analysis of drugs in urine, Analytical Chemistry, 1 (3), 7502-7508.

Lachenmeier, D.W. \& Rehm, J. (2015) Comparative risk assessment of alcohol, tobacco, cannabis and other illicit drugs using the margin of exposure approach, Scientific Reports, 5 (1), 2046-2322.

Laskin, J. \&Lanekoff, I. (2016) Ambient mass spectrometry imaging using direct liquid extraction techniques, Analytical Chemistry, 88(4), 52-73.

Llah, S.U., Noor, F., Khan, R.A. \& Bashir, S. (2016) Reliability of chemical identification doe law enforcement agencies: a forensic perspective, Journal of Research in Forensic Medicine and Toxicology, 2 (4), 14-17.

Lum, G. \& Mushlin, B. (2004) Urine drug testing: approaches to screening and confirmatory testing, Laboratory Medicine, 6 (1), 1-6.

Miao, Z. \& Chen, H. (2009) Direct Analysis of Liquid samples by desorption electrospray ionization-mass spectrometry (DESI-MS), Journal of American Society for Mass Spectrometry, 20, 10-1.

Mirabelli, M.F., Wolf, J.C. \& Zenobi, R. (2016) Direct coupling of solid-phase microextraction with mass spectrometry: sub-pg/g sensitivity achieved using a dielectric barrier discharge ionization source, Analytical Chemistry, 88 (9), 7252-7258.

Morelato, M., Beavis, A., Kirkbride, P. \& Roux, C. (2013) Forensic applications of desorption electrospray ionization mass spectrometry (DESI-MS), Forensic Science International, 226 (32), 10-21.

Palacios, C.C. \& Lanekoff, I. (2016) Direct analysis of pharmaceutical drugs using nano-DESI MS, Journal of Analytical Methods in Chemistry, 1 (1), 6.

Peters, F.T. (2013) Drugs of abuse: types and methods of analysis, Forensic Drug Analysis, 1 (1), $72-86$.

Roach, P.J., Laskin, J. \& Laskin, A. (2010) Nanospary desorption electrospray ionization: an ambient method foe liquid-extraction surface sampling in mass spectrometry, Analyst, 9 (2), 2161-2452.

Rosting, C., Pedersen-Bjergaard, S., Hansen, S.H. \& Janfelt, C. (2013) High-throughput analysis of drugs in biological fluids by desorption electrospray ionization mass spectrometry coupled with thin liquid membrane extraction, Analysts, 138 (11), 5965-5972.

Rutkowska, M., Dubalska, K., Konieczka, P. \& Namiesnik, J. (2014) Microextraction technique used in the procedures for determining organomercury and organotin compounds in environmental samples, Molecules, 19 (1), 7581-7609. 
Sun, X., Miao. Z., Yuan, Z., Harrington, R.D.B., Colla, J. \& Chen, H. (2011) Coupling of single droplet microextraction with desorption electrospray ionization-mass spectrometry, International Journal of Mass Spectrometry, 301, 102-108.

Takáts, Z., Wiseman, J.M., Gologan, B. \& Cooks, G. (2004) Mass spectrometry sampling under ambient conditions with desorption electrospray ionization, Science, 306 (14), 471-473.

Takáts, Z., Cotte-Rodriguez, I., Talay, N., Chen, H. and Cooks, G. (2005) Direct, trace level detection of explosives on ambient surfaces by desorption electrospray ionization mass spectrometry, Chemical Communication, 1 (1), 1950-1952.

Unites Nation Office on Drugs and Crime (2015) World Drug Report, at https://www.unodc.org/documents/wdr2015/World_Drug_Report_2015.pdf, visited 20 October 2016

Xie, L., Zhao, H., Zhou, P., Zhu, T., Liu, Y. \& Chen, H. (2015) Ambient mass spectrometry for forensic analysis, Annals of Forensic Research and Analysis, 2, 1021-1024.

Yazdi, A.S.\&Amiri, A. (2010) Liquid-phase microextraction, Trends in Analytical Chemistry, 29 (1), 1-14.

Zheng, Q. \&Chen, H. (2016) Development and applications of liquid sample desorption electrospray ionization mass spectrometry, Annual Review, 9 (3), 411-448. 